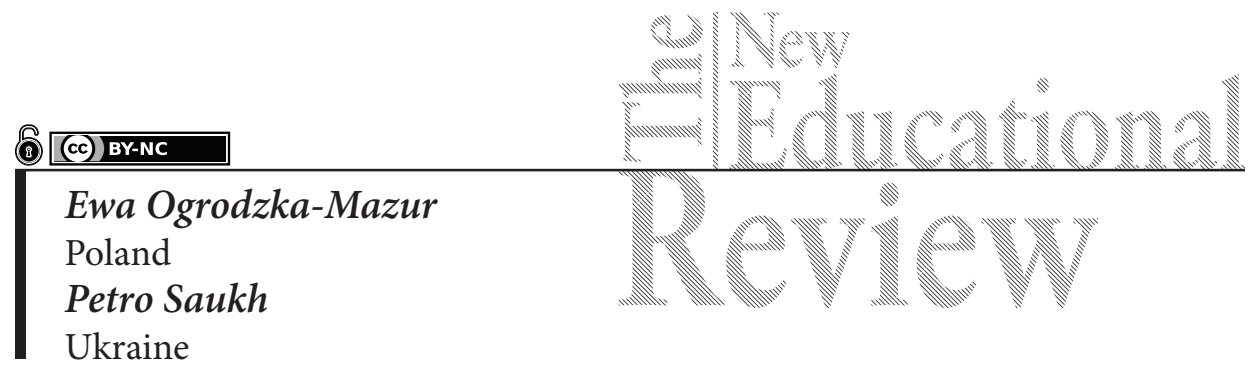

\title{
The Social and Cultural Tendencies in the Environment of Contemporary Youth. A Polish-Ukrainian Comparative Study of the Structure of Axiological Reality
}

DOI: 10.15804/tner.2019.57.3.05

\begin{abstract}
The theoretical and methodological framework of the undertaken issue is indicated by basic notional categories - culture, value and valuing orientations. While analyzing the philosophical and educational context, assumptions of social and cultural anthropology were applied (with a special focus on its anthropocentric-cultural current), (phenomenologically orientated) axiology and cognitive psychology (with the use of its cognitive-developmental theories). Assumption was also made concerning the exploration of youth's image of the axiological world and the valuing orientations manifested by them, that make it possible to learn the way(s) rooted in culture and experience, in which learners understand themselves, Others and the world.

Referring to the results of the studies conducted in 2001-2018 in a few selected cultural borderlands of Poland with European countries (Austria, Germany, Czech Republic) and Ukraine, the undertaken discussion draws attention to the problem of shaping the multidimensional identity of young Poles and Ukrainians, as well as the individual structure of the axiological reality.
\end{abstract}

Keywords: social and cultural tendencies, youth environment, generation gap, values, value orientations, multidimensional cultural identity, comparative study 


\section{Introduction: Contemporary cultural contexts versus axiological (un)consciousness of the young generation}

The youth living at the turn of the centuries is a new generation, quite different from their peers in previous generations. Their specificity and dissimilarity originates from the sociocultural, political and economic situation of the discussed countries, Europe and the world - the situation which becomes an important reference point. In the conditions of accelerated changes associated with globalization and transformational processes, the traditional order of values has been staggering - the values which pertain to particular human, social or economic situations gain growing acceptance. The observation of social life seems to indicate a relation between the contemporary cultural crisis and the crisis of orientation and valuing capability of the young. The contemporary youth do not share any longer the common worldview, axiology and a communication code, as it took place in postwar or post-Communist times. The young are a generation characterized by a growing diversity of attitudes and evaluations, specifically lost, reflective and focused on their own existence (Robertson, 1992; Inglehart, Welzel, 2007; Ptoukha, 2010; Kucharczyk, Łada, Schöler, 2017, pp. 127-137) .

Taking into account the sociocultural context, in the development of an individual axiological awareness allows for indicating its significant relations with such issues as subject-orientation, intentionality and identity. Despite many studies and analyses in this field, these problems are still divergent, open and dispersed over different scientific disciplines and subdisciplines. The political, economic and sociocultural changes to which Polish and Ukrainian society (as well as the European Union and other countries or nations) have been subjected over the last decades, are expressed in the same new approach and many different ways of understanding the world, different values, lifestyles and views (Arnett, 2000, pp. 470-479; Klimstra, Luyckx, Branje, Teppers, Goossens, Meeus, 2013, pp. 1661-1673; Datsko, 2015, pp. 75-88; Dlugosz, 2016, pp. 11-26).

The shaping of the new sociocultural order is favourable for some axiological transformations, among which the ones taking place in life should be distinguished from the transformations of values that have been objectivized in culture, and are comprised in the objects created by this culture.

Looking into many studies conducted in this field allows us to specify some typical features in the image of values which the contemporary youth share, for instance:

- a quality of the social knowledge of the "transformation generation" that there is no awareness of their own generational distinctiveness; 
- the level of the whole system of values is decreasing and the tendency to focus on life for oneself is increasing on a cross-generation scale;

- the significance of individual-private values is growing, contrary to the values of a social character, which are promoted by various (also educational) institutions;

- a new type of personality is being shaped, for which the model is self-fulfillment understood as conduct in compliance with the individual's potentialities and needs and, at the same time, in rejection of any ideology (including religious) (Siwko, 2006, pp. 89-104; Ogrodzka-Mazur, Grabowska, Szafrańska-Gajdzica, Kwadrans, 2016; Zarembo, 2017; Ogrodzka-Mazur, 2018, pp. 34-54; Sydyknazarov, Karzhaubay, Sydyknazarova, Bayurzhan, 2018, pp. 137-148).

\section{Highly rated values of the youth from Poland and abroad}

The authorial research conducted in 2002-2018 in Polish cultural borderlands (Polish-Belarussian, Polish-Czech, Polish-German and Polish-Slovak), as well as in some selected European countries (Austria, Germany, Czech Republic) have undertaken an important problem of shaping the multidimensional cultural identity of young Poles and their individual structure of the axiological reality ${ }^{1}$. The current use of the strategy of longitudinal comparisons is based on time criterion and it is aimed at understanding the mechanisms of change and the factors which affect the behaviour of groups and individuals living in the same socio-economic and cultural period. This made it possible not only to present the inner dynamics of change in the values most highly rated by contemporary youth, but also to capture certain mechanisms that determine this change (Marshall, 2014).

1 The studies have been conducted within the following projects: (1) Social, pedagogical and cultural determinants of the development and education of children and youth in the borderlandthe research conducted since 1990 in the Faculty of Ethnology and Education at the University of Silesia by the Department of General Pedagogy (project supervisor: T. Lewowicki, E. Ogrodzka-Mazur), (2) The child's acquisition of axiological competence in the situation of multicultural borderlands - a project financed in 2002-2005 by the State Committee for Scientific Research (KBN) (project coordinator: E. Ogrodzka-Mazur), (3) Education of children in Polish schools abroad: culturalization strategies - feeling of identity - cultural distance - project financed in 2011-2014 by the National Science Centre (NCN) (project supervisor: E. Ogrodzka-Mazur) and (4) Cultural identity and education of learning young adults in selected countries of East-Central Europe (project supervisor: E. Ogrodzka-Mazur). In total, 2300 secondary school learners and B.A. students took part in the studies conducted in 2002-2018. 
The respondents' axiological preferences were established based on the Scheler Value Scale (SVS) ${ }^{2}$, which enables one to specify the significance of particular values and their categories (groups) and to compare them to the model Scheler hierarchy. Each of the 50 values of SVS is evaluated separately on an estimation scale of 101 points. Referring the obtained raw results to norms allowed for outlining the profiles of values accepted by learners and university students, as well as for specifying how highly (in comparison to the normative group) they rank particular values.

The profiles of the values, which learners from various types of schools and cultural environments rank most highly, were made on the basis of the analysis of descriptive statistics. This was aimed at comparing them and at specifying the similarities and differences in respondents' axiological preferences. The data comprised in Figures 1,2 and 3 show the characteristic (for a social breakthrough) profile of axiological predispositions of the Polish youth in reference to their peers living in, among other countries, Austria, Germany and the Czech Republic. The lack of evident dominating values and the clearly flattened character of the whole structure might confirm that the youth is still not convinced what is important

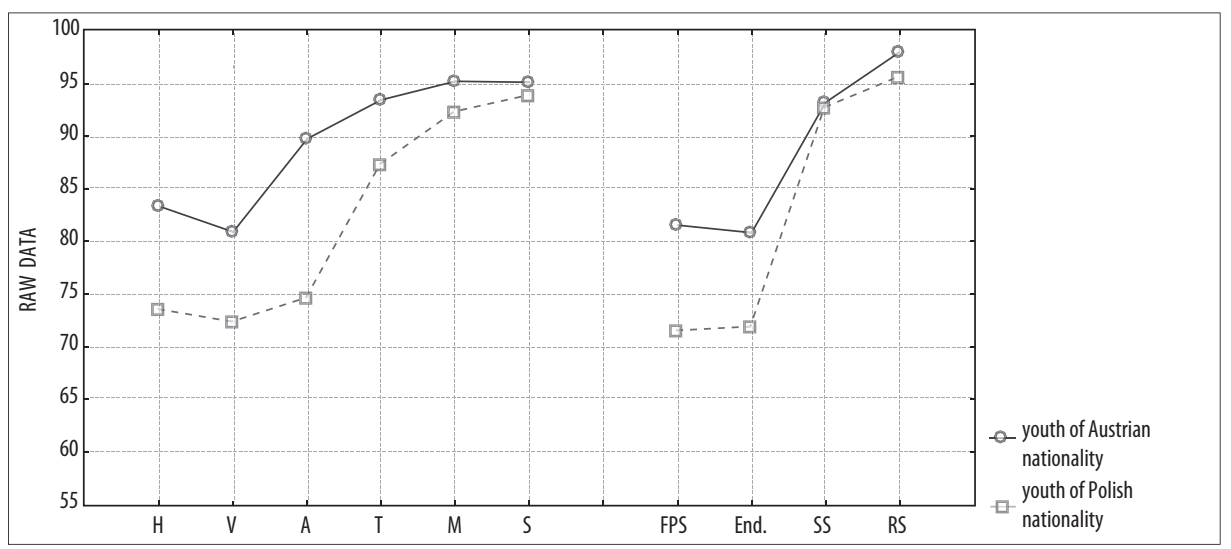

Figure 1. The profiles of values highly ranked by youth from the Austrian environment (raw data - basic scales and factor subscales)

${ }^{2}$ Scheler Value Scale (SVS) consists of 50 values, which make up 6 basic subscales comprising the following values: /H/ Hedonistic (affluent life, erotic love, possessing, pleasure, joy of life, comfort, relaxation, exciting life); /V/ Vital (stamina, physical strength, fitness, body flexibility, cold endurance, hunger endurance); /A/ Aesthetic (elegance, good taste, harmony, order of things, shape proportionality, regularity of lines, good organization); /T/ Truth (intelligence, 


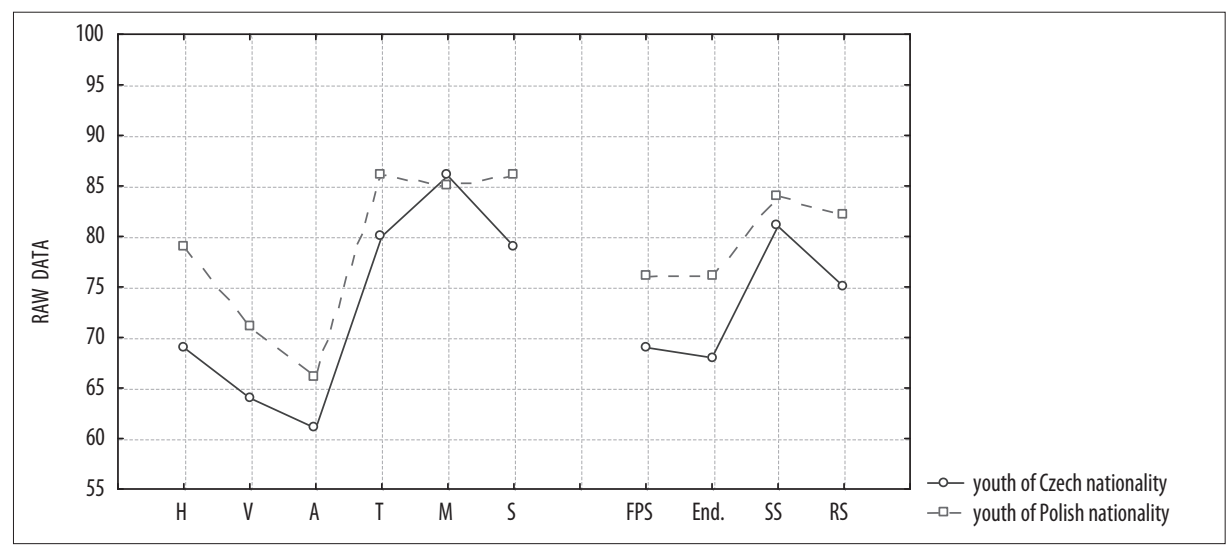

Figure 2. The profiles of values highly ranked by youth from the Czech environment (raw data - basic scales and factor subscales)

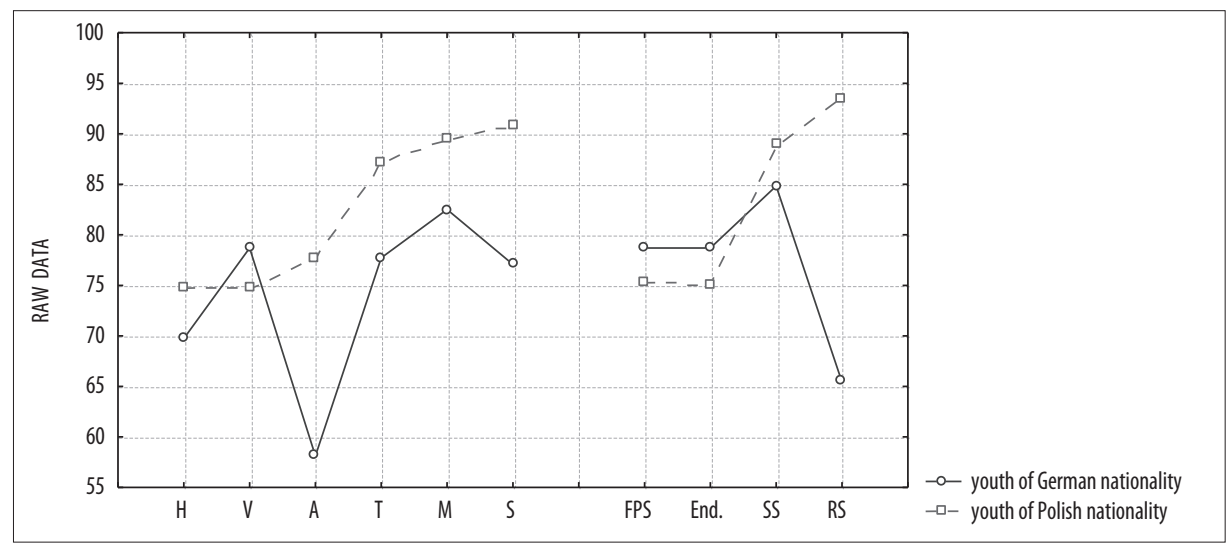

Figure 3. The profiles of values highly ranked by youth from the German environment (raw data - basic scales and factor subscales)

\section{BASIC SCALES FACTOR SUBSCALES}

$\mathrm{H}$ - subscale of hedonistic values FPS - subscale of fitness and physical strength

$\mathrm{V}$ - subscale of vital values End. - subscale of endurance

A - subscale of aesthetic values SS - subscale of secular sanctities

$\mathrm{T}$ - subscale of truth values RS - subscale of religious sanctities

$\mathrm{M}$ - subscale of moral values

$S$ - subscale of sacred values

Source: own research. 
in their life, as the ranks of values at consecutive positions are spaced at small distances and they can change their places.

Truth and moral values are at their proper position in the structure (in compliance with the objectivistic approach to values, represented in Max Scheler's phenomenological concept), which also confirms their universal character. There is higher position of this group of values among the Polish youth in comparison to the results of other studies (Youth, democracy and politics: Poland. Survey results, 2018). This may be interpreted as realizing by young people both the significance of knowledge and education in the conditions of a free market economy, and the fact that the quality of acquired qualifications determines their life, their future profession, work, position, living standards, and the fulfilment of their own goals and aspirations.

Yet, an evident revaluing has taken place in the case of religious values. According to James W. Fowler's model of religious faith, the religiousness of the surveyed youth is at the individual-reflective stage, associated with the emerging self-consciousness of a young person as regards relativity of the inherited religious worldview, alongside the rejection of the authorities which have been recognized so far (2000, pp. 37-61). This situation results in an increasingly critical attitude to almost all areas of life in which a growing up person functions and, at the same time, in developing the ability to reflect on one's own identity and ideology. In the declarations of Polish respondents from all the examined environments, religious sanctities most often get the highest average among all the groups of values (75.8). For almost a half of the respondents (48.5\%), the highest value - out of the 50 comprised in Scheler Value Scale, which can obtain the maximum number of points - is God. Other respondents who declared their attitude to religion as being "a non-practicing believer" or "hesitant in religious issues", always rank highly other values in this subscale, for instance: eternal life and salvation. Similar axiological preferences are manifested by the Austrian youth. The learners from

logical thinking, wisdom, objectivity, open mind, understanding, broad intellectual horizons, knowledge); /M/ Moral (goodness, honour, brotherly love, peace, helping others, truthfulness, reliability, sincerity, kindness, friendliness); /S/ Sacred (God, country, nation, independence, homeland, state, patriotism, religious faith, salvation, eternal life). In statistical analyses, apart from basic scales, 4 factor subscales were distinguished. The subscale of vital values breaks into two factor subscales: /FPS/ Fitness and Physical Strengthj (physical strength, fitness, body flexibility) and /End./ Endurance (resistance to tiredness, cold endurance, hunger endurance). The subscale of sacred values also breaks into two factor subscales /SS/ Secular Sanctities (country, nation, independence, state, patriotism) and /RS/ Religious Sanctities (God, faith, salvation, eternal life) (Brzozowski, 1995, pp. 14-15). 
the Czech Republic and Germany have a different, much lower profile of highly rated religious values.

Although in the questionnaire the attitude of the Polish youth to faith, religion and God was unambiguously specified by the highest ranks, the opinions of young people on the role of religion and the Church in their life were rather moderate and even partially contradictory. Some confirm the phenomenon of weakened religiousness both in Poland and worldwide, others emphasize a revival in searching and discovering new symbols of religious faith. In the opinion of $39.4 \%$ of respondents, the return to God, discovering Him anew, does not have to mean a return to the Catholic, Protestant, Orthodox or another Church. The institutional renaissance of religion is expressed not only in a return to traditional forms of religiousness, but also in the pluralization of religious life, the sign of which is the birth of new religious movements (sects and cults). Among the youth surveyed in 2018, 28.2\% declared attempts to contact other religious groups - in comparison with in 2012-19.4\% and in 2002-2006-6.5\%. According to the majority of respondents, religion is a private matter of every person. Therefore, as in traditional societies, this does not indicate the whole of the attitude to the world but becomes one of the segments of an individual's experience. Thus, religion and religiousness are more and more often the values individually (personally) chosen, however - they are losing the rank of values "inherited" only by "being" a member of a particular family or a socio-cultural community (Ogrodzka-Mazur, Szafrańska, Malach, Chmura, 2019).

Secular sanctities go through a kind of crisis. In the social awareness of the respondents surveyed in 2002-2018, these values ceased to be essential elements and fundamental mechanisms which consolidated particular groups and the whole Polish society. What appears here is an obvious tendency to seek a new semantic formula (both in the linguistic and symbolic sphere) for this group of values in the context of the occurring socio-political and cultural changes in Poland, Europe and the world. Thus, such values as the country, nation, independence, homeland, state, patriotism are not very significant for the young generation. However, it can be also assumed that the lack of manifestation of patriotic attitudes by the respondents might result from their lack of feeling any threat to the sovereignty of Poland and other countries.

The general image of axiological preferences of the surveyed youth from Poland shows a decrease in the overall level of the system of values. Yet, we observe a growing tendency to focus on life for oneself, an increasing significance of individual-private values - contrary to society-oriented values - as well as aiming at 
self-fulfilment, understood as conduct in compliance with one's potentialities and needs and in rejection of any ideology, including the religious.

\section{Structure of the axiological reality of Ukrainian youth}

The matrix of the modern youth environment in Ukraine, as well as in Poland, is predetermined by the pancivilizational matters. The first such issue is the balance of life-giving existential components of the human being in the current conditions. Nowadays society faces two ambivalent value orientations. In one respect, it is concerned with universal fundamental values, such as good, truth, mutual respect beauty that are related to the existential component "to be". On the contrary, the society deals with material, utilitarian values (money, wealth, power) which are invoked from the perspective of governing and consumerism and which comprise the existential component "to have". Regardless of the country of residence, the youth gives a higher rank to the existential "to have" as compared to the senior generation. The second issue is the (non)perception of the new, the differentiation of the distribution of innovations in society. Modern opinion surveys prove a serious differentiation in the youth environment, as compared to the senior generation, in relation to accepting current developments and the craving for risks. As it turned out, the young generation is far more open to innovations and taking risks than the older one. The third issue includes the amplification and intensification of the social and cultural reality, accompanied by the annihilation of traditions and norms, rapid and overall distribution of mass culture products. The techmarket orientation of modern civilization, having reached a sort of the cult of easiness in all aspects, is of particular interest to the youth. Finally, the fourth issue, being of a local character, is related to the imperfection of the society and the economic instability in Ukraine. In total, it preconditions the peculiarities of the trends in the contemporary Ukrainian society. According to numerous social studies, the major problems the youth is faced with are the following: (a) economic instability in the country $(63.3 \%)$; (b) decrease in the population's living standards (60\%); (c) corruption and incompetence of the ruling authorities (50.5\%); (d) the problem of employment (52\%) and war actions in Eastern Ukraine (49.2\%). In consequence, only $6.5 \%$ of the young feel happy, according to the rates of social negativism. Two thirds of the young people do not see any social prospects in Ukraine (Saukh, 2017, pp. 32-33). 
The four matters altogether outline five major trends in the environment of contemporary Ukrainian youth. The first is the dramatic change in value orientation. Everything that is not connected with the principles of governing (honour, compassion, friendship, love, consciousness, etc.) is being pushed into the background and deprived of social and cultural prestige. Thus, the strong influence of morals on everyday behavior is admitted only by $43.7 \%$ of the young people. Every tenth young person is not influenced by moral norms, while only $3 \%$ of the young generation are concerned with the idea of "a clear conscience" as the prior condition of happiness. As a result, modest social roles do not satisfy the young and are considered to be the loser's fate. The second trend is the destruction of traditional social and cultural norms and rules of behavior. There is a constant rise in the role of the subcultural component in the youth environment, which constitutes the ground for emerging new social and cultural communities (silver-spooners, liubers, yuppies, ravers, streetworkouts, cyberpunks, hiphoppers, emos, diggers, etc.). These non-formal groups comprise nearly $7 \%$ of the youth - they tend towards moral relativism, embrace the cult of physical force, criminal orientation, annihilation of everything created by the previous generations, heterogenocidal behavior. Under the conditions of political instability some non-formal groups become dangerous, as far as they are flexible enough to become an instrument in the hands of radical or extremist political organizations.

The third trend is a decrease in intellectual culture, compensated by mass culture orientation. There is a specific way of perceiving the world through a peculiar system of "intellectual values" constituting the foundation of youth subcultures: the desire to live a life of pleasure, a priority for consumerist orientation and "easy money", the rejection of social canons and applying the alternative position, which opposes the existing one. Civic engagement is extremely low. About $80 \%$ of the youth participate in public organizations, $22 \%$ are engaged in politics without expecting high performance of their social and political activity, only $1.9 \%$ visit libraries. The youth do not trust the law, moreover, every fifth ignores it. Only $30.6 \%$ think that the laws affect their everyday life (Tsinnosti ukrainskoi molodi..., 2016, pp. 73-75). Unlike the older generation, the youth find justification for avoidance of taxes, robbery, bribery, perjury, unlawful government assistance, etc. At the same time there is a growing interest in religion which helps all layers of the young to solve the problems of morality and spiritual life in the conditions of meaningful traditional sources of axiological consciousness. Over $50 \%$ of young people pray and go to church. The number of young believers increases annually. 
The fourth trend - the transformation of the spare time sphere in youth's life - is often accompanied by criminalization, owing to alcohol, drug or crime abuse. Large parts of Ukrainian young people (28.4\%) spend their free time outdoors and in night clubs. Over the last 10 years, the number of drug addicts has increased 6-8 times. In the communication aspect, the sphere of youth's spare time is even more vulnerable - the processes of computerization and commercialization are even more rapidly developing. E-communication increases the opportunities of creative activity, fulfils informational, educational and cultural demands, and opens an unlimited space for socializing and self-expression. However, this is often related to financial fraud, hacking, misinformation, seduction (porn industry, computer games etc.), promoting violence, neglecting the ethic norms of behaviour. The fifth trend focuses on establishing and developing a new digital " $Z$-generation" imbued with a spirit of hedonism, easily harmed, denying the thought-leaders, tending towards freedom and individual life space. A sense of responsibility not only for oneself, but also for the surrounding world is a characteristic feature of this generation. Zs possess large-scale information, take innovations easily and implant the knowledge from one sphere to another. They skillfully combine spontaneity, mature abilities and understanding of the depth of life. There are no boundaries for this generation. Despite the fact that the age of the young varies from 14 to 20 , they are extremely responsible and serious and have a conscientious attitude towards justice as well as gender, race and social equality.

At the same time, the opinion surveys have proved that a large part of Ukrainian youth treats traditional values as the top priority. The first three positions in the hierarchy of values are: family happiness $(71.7 \%)$, health $(55.8 \%)$ and career (48.1\%); $44.9 \%$ of the young want to live in Ukraine and do not plan to emigrate (Saukh, 2017, pp. 30-36). Thus, the vast majority of young Ukrainians (88\%) want their country to be subjected to dramatic large-scale changes.

\section{Conclusions}

The surveyed youth is quite diversified due to qualitative, social and economic characteristics, pertaining not only to certain categories and social groups but also to regions. Most generally, there are no grounds to criticize or to idealize the youth. As regards its highly differentiated scales of values, the self-awareness of the conflict merely reflects the tectonic movements in the economic, social and cultural spheres of Ukrainian life. The youth's perplexity is a natural result of their lack of experience. The young observe the conflicts, paradoxes and calamities 
of the society from the outside, and therefore they initiate social changes. This is an objective fact to face and to understand. However, to make these changes grounded and constructive, a brand new algorithm is needed of the state for youth policy that must be based on an up-to-date educational system.

Considering all the aspects mentioned above, the following steps are to be taken urgently:

- to initiate a number of reforms in social politics and education, providing or re-establishing a system of social lifts, i.e. mechanisms that enable an increase in the social and economic status of the young people, and determine their career development alongside their abilities and competence;

- to form a flexible educational system based on the ideas of the so called "new humanism", aimed not at idealizing humanity or denying the antihumanity, but at accepting the fact that all the people are bound in the good and the bad. Thus, youth consumerism should not be criticized by means of moral arguments, the youth should rather be equipped with the skills and abilities to provide the conditions for existence: "to have" for the sake of "to be" in the context of human dignity;

- to redirect the academic and educational process from the partial (intellectual, moral, national and patriotic, aesthetic, physical, etc.) education of a young person to holistic intellectual education. This should lead to empathy which prevents offences, hatred, cruelty, aggression, stress, and pessimism;

- to concentrate the efforts of the academic and educational system not only on training creative innovators capable of solving complex problems or operating the principles of "tying up" the knowledge and providing it with a new sense, but also on turning this knowledge into life wisdom which will become a cognitive expertise of all fundamental life practices.

\section{References}

Arnett, J.J. (2000). Emerging adulthood. A theory of development from the late teens through the twenties. American Psychologist, 55 (5), 470-479.

Brzozowski, P. (1995). Skala Wartości Schelerowskich - SWS. Podręcznik [Scheler Value Scale - SVS. Handbook]. Warszawa: PTP. Datsko, O. (2015). Culture of socio-economic security of Ukraine: challenges in $21^{\text {st }}$ century. Securitologia, 1, 75-88.

Dlugosz, P. (2016). Youth in the situation of anomie in the East-Central Europe borderlands. Youth in Central and Eastern Europe. Sociological Studies, 2 (6), 11-26. 
Fowler, J.W. (2000). Becoming adult, becoming Christian: adult development and Christian faith. San Francisco: Jossey-Bass Publishers.

Inglehart, R., \& Welzel, Ch. (2007). Modernization, cultural change and democracy: the human development sequence. New York: Cambridge University Press.

Klimstra, T.A., Luyckx, K., Branje, S., Teppers, E., Goossens, L., \& Meeus, W.H.J. (2013). Personality traits, interpersonal identity and relationship stability: longitudinal linkages in late adolescence and young adulthood. Youth Adolescence, 42 (11), 1661-1673.

Kucharczyk, J., Łada, A., \& Schöler, G. (eds) (2017). Exit, voice or loyalty? Young people on Europe and democracy. Case studies from Austria, the Czech Republic, Germany, Hungary, Poland and Slovakia, 127-137 http://www.isp.org.pl/publikacje,25,944.html (access: 8.04.2019).

Marshall, J. (2014). Introduction to comparative and international education. Los Angeles London - New Delhi - Singapore - Washington: Sage Publications Ltd.

Ogrodzka-Mazur, E., Grabowska, B., Szafrańska-Gajdzica, A., \& Kwadrans, Ł. (2016). Education of children and youth in culturally diverse environments: experiences - problems - prospects. Munich: Lincom Academic Publishers.

Ogrodzka-Mazur, E. (2018). Values highly ranked by young Poles and their life aims - individual and community resources in building the borderland capital. In: T. Lewowicki, E. Ogrodzka-Mazur, B. Chojnacka-Synaszko, \& U. Klajmon-Lech (eds). Spheres of spiritual life - a study on permanence and changeability of identity behaviours in borderland communities. Munich: LINCOM Academic Publishers, 34-54.

Ogrodzka-Mazur, E., Szafrańska, A., Malach, J., \& Chmura, M. (2019). Cultural identity and education of learning young adults in selected countries of East-Central Europe. A Polish-Czech comparative study. Toruń: Wydawnictwo Adam Marszałek (in print).

Ptoukha, K. (2010). Youth and youth policy in Ukraine: social and demographic aspects. Kyiv: Institute for Demography and Social Studies of the NAS of Ukraine.

Robertson, R. (1992). Globalization. Social theory and global culture. London: SAGE Publications.

Saukh, P.Y. (2017). Sotsiokulturni tendentsii v suchasnomu molodizhnomu seredovyshchi: tsyvilizatsinyi vymir [Social and cultural trends in modern youth environment: civilizational dimension]. Pedahohika i Psykholohiia/ Pedagogy and Psychology, 4 (97), 30-36.

Siwko, M. (2006). Values and aspirations of the Polish youth in the contemporary Europe. Yearbook of Polish European Studies, 10, 89-104.

Sydyknazarov, M-A., Karzhaubay, J., Sydyknazarova, S., \& Bayurzhan, M. (2018), Values of the youth of Kazakhstan. The New Educational Review, 52 (2), 137-148.

Youth, democracy and politics: Poland. Survey results (2018). NDI/IPA https://www. ndi.org/publications/youth-democracy-and-politics-public-opinion-research-poland (8.04.2019).

Zarembo, K. (2017). Ukrainian “Generation Z”: attitudes and values. Kyiv: Friedrich-EbertStiftung. 